\title{
Improved burn wound healing by the antimicrobial peptide LLKKK18 released from conjugates with dextrin embedded in a carbopol gel
}

\author{
João P. Silva a,b,*, Sandeep Dhall ${ }^{\mathrm{a}, \mathrm{c}}$, Monika Garcia ${ }^{\mathrm{a}}$, Alex Chan ${ }^{\mathrm{a}}$, César Costa ${ }^{\mathrm{b}}$, Miguel Gama ${ }^{\mathrm{b}}$, \\ Manuela Martins-Green ${ }^{\mathrm{a}, \mathrm{c}}$ \\ a Department of Cell Biology and Neuroscience, University of California at Riverside, Riverside, CA 92521, United States \\ ${ }^{\mathrm{b}}$ CEB - Centre for Biological Engineering, University of Minho, Campus de Gualtar, Braga 4710-057, Portugal \\ c Bioengineering Interdepartmental Graduate Program, University of California at Riverside, Riverside, CA 92521, United States
}

\section{A R T I C L E I N F O}

\section{Article history:}

Received 17 February 2015

Received in revised form 12 June 2015

Accepted 29 July 2015

Available online 30 July 2015

\section{Keywords:}

Succinoylation

Oxidative stress

Angiogenesis

Macrophage

Inflammation

\begin{abstract}
A B S T R A C T
Antimicrobial peptides (AMPs) are good candidates to treat burn wounds, a major cause of morbidity, impaired life quality and resources consumption in developed countries. We took advantage of a commercially available hydrogel, Carbopol ${ }^{\circledR}$, a vehicle for topical administration that maintains a moist environment within the wound site. We hypothesized that the incorporation of LLKKK18 conjugated to dextrin would improve the healing process in rat burns. Whereas the hydrogel improves healing, LLKKK18 released from the dextrin conjugates further accelerated wound closure, and simultaneously improving the quality of healing. Indeed, the release of LLKKK18 reduced oxidative stress and inflammation (low neutrophil and macrophage infiltration and pro-inflammatory cytokines levels). Importantly, it induced a faster resolution of the inflammatory stage through early M2 macrophage recruitment. In addition, LLKKK18 stimulated angiogenesis (increased VEGF and microvessel development in vivo). Moreover, collagen staining evaluated by Masson's Trichrome was visually much more intense after treatment with LLKKK18, suggesting higher collagen deposition.

Overall, we generated an effective, safe and inexpensive formulation that maintains a moist environment in the wound, easy to apply and remove, and with potential to prevent infection due to the presence of an antimicrobial peptide. These findings propel us to further study this LLKKK18-containing formulation, setting the foundations towards a potential therapeutic approach for burn wound treatment.
\end{abstract}

\section{Statement of Significance}

This work presents a newly developed formulation that holds great potential as a therapeutic approach for burn treatment. It is based on the sustained delivery of an antimicrobial peptide - LLKKK18 - from conjugates with dextrin, after degradation of dextrin backbone upon exposure to wound $\alpha$-amylases. Conjugates were further embedded in Carbopol $^{\circledR}$, a commercially available hydrogel, suitable for topical administration and that provides a moist environment to the wound. Overall, we obtained an efficient, safe and non-expensive formulation that improves burn wound healing, maintains a moist environment within the wound, is easy to apply-and-remove, and has potential to prevent infection due to the presence of an antimicrobial peptide. Importantly, this is the first time the wound healing ability of LLKKK18 is demonstrated and that its main mechanisms of action are identified.

(c) 2015 Acta Materialia Inc. Published by Elsevier Ltd. All rights reserved.

\section{Introduction}

Burn wounds are a major cause of morbidity and reduced quality of life and, in developed countries, they take up substantial

* Corresponding author at: CEB - Centre for Biological Engineering, University of Minho, Campus de Gualtar, 4710-057 Braga, Portugal.

E-mail address: jpsilva@deb.uminho.pt (J.P. Silva). health resources [1]. According to the World Health Organization burns affect more than 100 million people worldwide every year. Indeed, each European Union member spends on average $2-4 \%$ of the health budget in wound care and in the US alone $\$ 7.5$ billion are spent every year for burn wound treatment [2]. Thus, developing safe, efficient, easy-to-use and inexpensive wound treatments became imperative. 
Hydrogels have been often studied for pharmaceutical and biomedical applications such as wound dressings and drug delivery systems. They are composed of cross-linked hydrophilic polymers with a very high intrinsic content of water, providing a semi-occlusive moist environment to the wound area, absorbing the exudates, reducing pain and healing time, and being painless on both application and removal [3]. The maintenance of a moist environment is particularly relevant as it promotes cell proliferation and collagen deposition [4]. Most important, among the different types of dressings available, hydrogels have been described as the most suitable for partial-thickness burn wounds [5].

Many therapeutic agents, including growth factors (e.g. EGF, TGF-beta) [6] and hormones [7] have been successfully used in wound treatment. However, their high production costs discourage their application [8]. In particular, antimicrobial agents like silver sulfadiazine, iodine or medical grade honey have been incorporated into dressings as a way of keeping the wounds safe from infections. However, many studies have shown that treatment with these agents alone is not sufficient to achieve complete wound healing and in some cases, toxicity problems can ensue [9].

In this sense, antimicrobial peptides (AMPs), which are commonly small, cationic and amphipathic peptides [10], arise as suitable candidates for wound therapeutics. LL37 is a peptide that belongs to the cathelicidin family of AMPs and is overexpressed in several different cell types. LL37, in addition to its antimicrobial activity, has been reported to be involved in mast cells and leukocytes chemotaxis, angiogenesis and in promoting wound healing $[11,12]$. Indeed, LL37 is overexpressed in the epidermis and within the wound itself after injury [10]. However, the molecular mechanisms involved in LL37 improvement of healing are not clear. Recently, a recombinant version of this peptide that was able to maintain its antimicrobial activity was produced using a cost-effective method [13]. This recombinant LL37 was shown to accelerate the dexamethasone-induced impaired healing of excisional wounds in C57BL/6 mice [14], further suggesting its potential use as an inexpensive therapeutic agent.

Analogs of LL37 have also been engineered to enhance its antimicrobial properties and to decrease cytotoxicity and binding to plasma protein $[15,16]$. One of them, LLKKK18, in which polar uncharged residues glutamine and asparagine, and negatively charged aspartic acid are substituted by positively charged lysine residues, displays higher hydrophobicity and cationicity than LL37. This results in higher antimicrobial and chemoattractant activity, as previously described [15]. However, to date nothing is known about the ability of LLKKK18 to improve wound healing.

Exogenous administration of these peptides is usually hampered by drug toxicity, as well as limited stability and solubility [17]. PEGylation has been used for a long time to enhance protein stability and improve pharmacokinetics and partially solves the problems with these peptides' administration, but cutaneous allergic reactions and the non-biodegradability of poly(ethyleneglycol) (PEG) may hinder its use [18]. A promising alternative is peptide conjugation with dextrin, using a succinoylation method previously described [19]. Dextrin is a FDA approved polysaccharide, non-immunogenic, biocompatible and efficiently excreted due to its low molecular weight [20]; some applications comprise the food and beverages industry (e.g. Cargill Inc. - São Paulo, Brazil) or paper and packaging industry (e.g. LD Davis Industries - PA, USA); dextrin stabilizes the peptide, protects it from proteases and constitutes itself a release system, as it degrades upon contact with the amylases present in wound tissue, releasing the peptide over time $[21,22]$.

In the work presented here we incorporated the DextrinLLKKK18 conjugates in a Carbopol ${ }^{\circledR}$ hydrogel for topical administration. Carbopol ${ }^{\circledR}$ is made of carbomers that are cross-linked to form a structure with good flow properties and buffering capacity, high viscosity, good biocompatibility, bioadhesive properties, good thermal stability and good patient acceptability [23]. Upon release from the hydrogel, dextrin degrades through the wound amylases action, releasing the peptide in a sustained manner. This makes it optimal for dermatological purposes, including wound healing [24]. To our knowledge, this is the first time that the therapeutic potential of LLKKK18 is evaluated.

\section{Materials and methods}

\subsection{Reagents}

Carbopol $^{\circledR} 974$ NF was a kind gift from Lubrizol Inc. (Ohio, USA). Custom synthesis of LLKKK18 was obtained from Schafer-N (Copenhagen, Denmark). Other reagents were obtained as follows: Dextrin (Tackidex ${ }^{\circledR}$ B 167) from Roquette (Lestrem, France); trichrome stain kit from ScyTek Laboratories (Logan, UT); ketamine, xylazine, buprenorphine, from Henry Schein (Melville, NY). All other reagents, unless stated otherwise, were purchased from Sigma Aldrich (Oakville, Canada).

\subsection{Dextrin modification}

Dextrin was succinoylated using a modified version of a method previously described by Hreczuk-Hirst et al. [25], based on the introduction of a carboxyl group in the dextrin backbone via an ester linkage, in a 4-dimethylaminopyridine (DMAP)-catalyzed reaction.

Briefly, $1 \mathrm{~g}\left(6.17 \times 10^{-3} \mathrm{~mol}\right)$ of dextrin $\left(\right.$ Tackidex $\left.^{\circledR}\right)$ with a $M_{\mathrm{w}} \approx 2000 \mathrm{Da}$ was dissolved in $10 \mathrm{ml}$ of anhydrous dimethylformamide (DMF). Dextrin succinoylation was achieved by subsequent addition of succinic anhydride $\left(3.70 \times 10^{-3} \mathrm{~mol}\right)$ and DMAP $\left(2.34 \times 10^{-4} \mathrm{~mol}\right)$. The flask with the reagents was purged with nitrogen, sealed and left stirring at $50{ }^{\circ} \mathrm{C}$ for $48 \mathrm{~h}$. The reaction mixture was then poured into $250 \mathrm{ml}$ diethyl ether and left stirring vigorously overnight, at room temperature. The ether was removed by vacuum filtration and the solid residues dissolved in $10 \mathrm{ml}$ of distilled water. The solution was dialyzed against $2 \mathrm{~L}$ of distilled water for $6 \mathrm{~h}$, with water being replaced every $2 \mathrm{~h}$, in a dialysis membrane with a molecular weight cut-off of $1000 \mathrm{~g} / \mathrm{mol}$. The dialyzed solution was freeze-dried and kept at room temperature until use. A final yield of about $90-95 \%$ was obtained. The ratio of reagents used was optimized to yield a modified dextrin that: (1) would have enough functional groups to bind LLKKK18, and (2) would be able to delay degradation by amylases in order to provide a sustained release of the peptide. The \% mol succinoylation, that is, the number of glucose monomers activated by succinic anhydride per 100 monomers, was determined by titration of the succinoylated dextrin with $\mathrm{NaOH}$. Due to the tendency of $\mathrm{NaOH}$ to absorb $\mathrm{CO}_{2}$ from the atmosphere, $\mathrm{NaOH}$ pellets were first dried and titrated with phthalic anhydride, prior to its use to titrate succinoylated dextrin. A batch with $8.8 \%$ mol succinoylation was obtained and used for all the subsequent experiments.

\subsection{Production of the Dextrin-LLKKK18 conjugates}

LLKKK18 was conjugated with dextrin, using a modified version of a method previously described [25], based on the binding of the peptide free amines to the free carboxyl groups in the succinoylated dextrin (DexSuc) backbone, which results in the formation of an amide. Briefly, $50 \mathrm{mg}\left(2.92 \times 10^{-4} \mathrm{~mol}\right.$ DexSuc, corresponding to $\left.2.6 \times 10^{-5} \mathrm{~mol} \mathrm{COOH}\right)$ of succinoylated dextrin were firstly dissolved in $1 \mathrm{ml} \mathrm{dH}_{2} \mathrm{O}$. 1-Ethyl-3-(3-dimethylaminopropyl) carbodiimide $\left(2.6 \times 10^{-5} \mathrm{~mol}\right)$ and N-hydroxysuccinimide $\left(2.6 \times 10^{-5} \mathrm{~mol}\right)$ were then added to the mixture and left stirring for $30 \mathrm{~min}$. LLKKK18 $\left(5.15 \times 10^{-7} \mathrm{~mol}\right)$, dissolved in $1 \mathrm{ml}$ of $\mathrm{dH}_{2} \mathrm{O}$, 
was subsequently added to the previous solution and the pH was raised to $\sim 8.0$ by the dropwise addition of $\mathrm{NaOH}$. The reaction mixture was left stirring overnight $(\sim 16 \mathrm{~h})$. Conjugates were separated from unbound peptide by passage over a desalting HiPrep 26/10 column (GE Healthcare, UK), using distilled water as the eluent. The product was freeze-dried and kept at $-80^{\circ} \mathrm{C}$ until use. The presence of the conjugates $\left(M_{\mathrm{w}} \approx 4,300 \mathrm{Da}\right.$ ) was detected by quantifying the amount of reducing sugars present in collected fractions through the DNS assay (after treating the fractions with $\alpha$-amylase) and by determining the amount of peptide by the Waddell's method [26]. Finally, dextrin-LLKKK18 conjugates were incorporated into a Carbopol $^{\circledR} 974$ NF (Lubrizol, Ohio, USA) hydrogel. A 0.5\% Carbopol ${ }^{\circledR}$ solution was prepared in distilled water, at $50^{\circ} \mathrm{C}$ for $1 \mathrm{~h}$, with stirring. The desired amount of conjugate was added to the solution until complete dissolution and the mixture was neutralized by the dropwise addition of $\mathrm{NaOH}$ until it reached a $\mathrm{pH}$ of 6-6.5.

\subsection{Burn wound model}

All animal protocols were approved by the Institutional Animal Care and Use Committee (IACUC) of the University of California Riverside (UCR). Female adult Sprague-Dawley rats, weighing around $200-240 \mathrm{~g}$ and obtained from the UCR vivarium, were housed under a $12 \mathrm{~h}$ dark/light cycle in a room with controlled temperature and humidity. Standard rat chow and water were supplied ad libitum. Prior to the experiments, rats were anesthetized with an intraperitoneal dose of $80 \mathrm{mg} / \mathrm{kg}$ ketamine and $16 \mathrm{mg} / \mathrm{kg}$ xylazine. A partial thickness burn wound was made on the shaved dorsum of the anesthetized rats with a $1.5 \mathrm{~cm}$ diameter brass cylinder heated in a water bath at $80^{\circ} \mathrm{C}$ for $2 \mathrm{~min}$ and pressed against the rat skin for $6 \mathrm{~s}$. This method was based on the protocol by Liu and colleagues [27]. Buprenorphine $(0.05-0.1 \mathrm{mg} / \mathrm{kg})$ was administered immediately after the burn to ease post-burn pain. At least 6 rats were used per group. About $250 \mu$ l of the Carbopol $^{\circledR}$ hydrogel, alone or incorporating either succinoylated dextrin or dextrin-LLKKK18 conjugates containing $15 \mu \mathrm{g}$ of LLKKK18, were topically applied every 3 days during the first 9 days post-burn. Phosphate Buffered Saline (PBS) topically administered using the same regimen was used to evaluate the recovery of the rat burn per se. A Tegaderm patch (3M, London, Canada) was applied on top of the wounds to keep the hydrogel in place over the burn. Wound tissues were collected $1 \mathrm{~h}$ after the burn was made and at 3, 6, 9, 12, 15 and 18 days for tissue analysis. Normal skin was also collected from an area distant from the burn for comparison. Photographs of the wounds were taken at the same defined time points using a digital camera placed at a distance of $4 \mathrm{~cm}$. Wound size was then determined with the aid of Image 1.46 software (NIH, Bethesda, MD) until re-epithelialization was achieved.

\subsection{Determination of oxidative stress levels}

Oxidative stress in the burn wounds was determined by measuring the activity of antioxidant enzymes in the tissue extracts. $40-50 \mathrm{mg}$ of collected burn tissue were homogenized in a bullet blender, for $5 \mathrm{~min}$ at $4{ }^{\circ} \mathrm{C}$, in the presence of zirconium oxide beads, and $10 \mu$ RIPA buffer (1\% NP-40, 0.1\% SDS, 50 mM Tris- $\mathrm{HCl} \mathrm{pH} 7.4$, $150 \mathrm{mM} \mathrm{NaCl}, 0.5 \%$ sodium deoxycholate, $1 \mathrm{mM}$ EDTA) per $\mathrm{mg}$ of tissue. Extracts were then centrifuged at $12,000 \mathrm{rpm}$ for $15 \mathrm{~min}$, at $4{ }^{\circ} \mathrm{C}$. The supernatants were either immediately used or aliquoted and stored at $-80^{\circ} \mathrm{C}$ for later use.

Determination of superoxide dismutase (SOD) activity was assessed using a commercially available kit (Cayman Chemical, Ann Arbor, USA), following the manufacturer's instructions. One unit of SOD was defined as the amount of enzyme required to induce $50 \%$ dismutation of the superoxide radical and results were expressed as $\mathrm{U} / \mathrm{ml}$ of tissue extract.
Hydrogen peroxide $\left(\mathrm{H}_{2} \mathrm{O}_{2}\right)$ levels were indirectly determined with a commercial kit (Cell Technology Inc., Mountain View, USA). This assay measures the amount of the fluorescent product resorufin formed upon $\mathrm{H}_{2} \mathrm{O}_{2}$-induced oxidation of the non-fluorescent substrate 10-acetyl-3,7-dihydroxyphenoxazine in a reaction catalyzed by peroxidase. Fluorescence was read at $530 \mathrm{~nm}$ (excitation)/590 $\mathrm{nm}$ (emission) in a Victor 2 microplate reader. The amount of $\mathrm{H}_{2} \mathrm{O}_{2}$ in the supernatants, which is proportional to the resorufin formed, was calculated from a $\mathrm{H}_{2} \mathrm{O}_{2}$ standard curve.

Catalase activity was measured by using a commercially available kit (Cayman Chemical, Ann Arbor, USA), according to the manufacturer's procedure. This assay makes use of the peroxidatic capability of catalase. This enzyme reacts with methanol to produce formaldehyde in the presence of an optimal concentration of $\mathrm{H}_{2} \mathrm{O}_{2}$. This formaldehyde was quantified spectrophotometrically at $540 \mathrm{~nm}$ using 4-amino-3-hydrazino-5-mercapto-1,2,4-triazole (purpald) as the chromogen. Upon oxidation, purpald-aldehyde complexes change from colorless to a purple color. Catalase activity was expressed as $\mathrm{nmol} / \mathrm{min} / \mathrm{ml}$.

Glutathione peroxidase (GPx) activity was measured indirectly by a coupled reaction with glutathione reductase (GR), using a commercially available kit (Cayman Chemical, Ann Arbor, USA). GPx reduces $\mathrm{H}_{2} \mathrm{O}_{2}$ to $\mathrm{H}_{2} \mathrm{O}$, while producing oxidized glutathione (GSSG) in the process. GSSG is then recycled back to its reduced state by GR and NADPH. Oxidation of NADPH to NADP ${ }^{+}$is accompanied by a decrease in absorbance at $340 \mathrm{~nm}$. Under rate-limiting conditions of GPx activity, the rate of decrease in the $\mathrm{A}_{340}$ is directly proportional to the GPx activity in the sample. This rate was measured at $1 \mathrm{~min}$ intervals during $5 \mathrm{~min}$ in a Victor 2 microplate reader and GPX activity was expressed as $\mathrm{nmol} / \mathrm{min} / \mathrm{ml}$ of tissue extract.

\subsection{Oxidative DNA damage}

To measure the amount of oxidative DNA damage, 5-6 mg of burn tissue were collected and homogenized in RIPA buffer, as described above. DNA was extracted using the DNeasy Blood and Tissue kit (Qiagen, Chatsworth, CA) according to the manufacturer's instructions. DNA concentration was measured and purity confirmed by calculating the $\mathrm{OD}_{260} / \mathrm{OD}_{280}$ absorption ratio. 8-hyd roxy-2'-deoxyguanosine (8-OH-dG) levels, which correlate with the amount of oxidative DNA damage, were measured spectrophotometrically at $405 \mathrm{~nm}$ using a DNA/RNA Oxidative Damage EIA kit (Cayman Chemical, Ann Arbor, USA), following the manufacturer's protocol.

\subsection{Lipid peroxidation assay}

The Thiobarbituric Acid Reactive Substances (TBARS) assay, which directly measures the amount of malondialdehyde (MDA) and 4-hydroxynonenal (4-HNE), was used to quantify the levels of lipid peroxidation in the tissues, using a commercially available kit (Cell Biolabs Inc., San Diego, USA). Samples were reacted with TBA at $95{ }^{\circ} \mathrm{C}$ for $1 \mathrm{~h}$ and the MDA content detected fluorometrically at $540 \mathrm{~nm}$ excitation/590 $\mathrm{nm}$ emission. TBARS levels were then calculated from a predetermined MDA standard curve.

\subsection{Protein nitration}

Nitrotyrosine levels, indicative of oxidative damage to proteins, were measured with an ELISA kit (Cell Biolabs Inc., San Diego, USA). Tissue samples were incubated in an ELISA plate with an anti-nitrotyrosine primary antibody, followed by a horseradish peroxidase (HRP)-conjugated secondary antibody. Nitrotyrosine content was then measured spectrophotometrically at $412 \mathrm{~nm}$ against a nitrated BSA standard curve. 


\subsection{Tissue histology}

Histological analysis was performed on wound tissues collected at specific time points after the burn was created. These tissues were excised in a way to include an area of about $5 \mathrm{~mm}$ around the wound edge and were immediately fixed in $4 \%$ paraformaldehyde overnight in the cold room on rocker. Subsequently, they were incubated for $1 \mathrm{~h}$ with $0.1 \mathrm{M}$ glycine, followed by sequential incubations with 15\% and 30\% sucrose, for $6 \mathrm{~h}$ and overnight, respectively. Tissues were then embedded in OCT (Tissue-Tek; Torrance, USA), frozen in dry ice and stored at $-80^{\circ} \mathrm{C}$. Sections were stained with Hematoxylin and Eosin. Connective tissue was analyzed by staining wound sections with a modified Masson's Trichrome stain (ScyTek Laboratories, Logan, UT), according to the manufacturer's protocol. Briefly, sections were fixed with Bouin's fluid, followed by staining with Weigert's hematoxylin and by incubation with Biebrich Scarlet/Acid Fuchsin. Differentiation was then performed in a phosphomolybdic/phosphotungstic acid solution, followed by incubation with Aniline Blue and acetic acid. Sections were dehydrated, mounted on a microscopy slide and visualized in a Nikon Microphot-FXA microscope with a Nikon DS-Fi1 digital camera. Collagen stained blue, keratin appeared red, cytoplasm stained pink and cell nuclei were black.

\subsection{Immunolabeling}

Frozen sections on microscopy slides were fixed in $4 \%$ paraformaldehyde for $20 \mathrm{~min}$, followed by an incubation with $0.1 \mathrm{M}$ glycine for $20 \mathrm{~min}$ and blocking in $10 \%$ non-immune serum of the secondary antibody species in PBS containing $0.1 \%$ Triton $\mathrm{X}-100$ for $30 \mathrm{~min}$. Slides were then incubated with the primary antibodies in 1\% BSA/PBS for $2 \mathrm{~h}$ at room temperature, as it follows: 1:200 FITC-labeled mouse anti-rat $\alpha$-smooth muscle actin ( $\alpha$-SMA, Sigma-Aldrich, St Louis, MO), 1:100 rabbit anti-rat F4/80 (Abcam, Cambridge, MA) and 1:100 rabbit anti-rat myeloperoxidase (MPO, eBioscience, San Diego, CA). Sections were then washed three times with $0.1 \%$ BSA in PBS and in the case of MPO incubated with 1:25 FITC-labeled goat anti-rabbit secondary antibody (Life Technologies, Grand Island, NY), for $1 \mathrm{~h}$ at room temperature. After washing, slides were mounted in Vectashield containing DAPI (Vector Laboratories, Inc. Berlingame, CA). Immunofluorescence was visualized and imaged using a Nikon Microphot-FXA fluorescence microscope with a Nikon DS-Fi1 digital camera and NIS-Elements software (Nikon Instruments Inc., Melville, NY).

\subsection{Cytokines expression}

Burn wound tissues were homogenized in RIPA buffer at $4{ }^{\circ} \mathrm{C}$ for 5-10 min, as described above. Total protein in the tissues was determined using the DC protein assay kit (Bio-Rad, Hercules, CA) and a ProcartaPlex ${ }^{\mathrm{TM}}$ Multiplex Immunoassay was performed according to the manufacturers' protocol (eBioscience, Carlsbad, CA). Levels of monocyte chemoattractant protein-1 (MCP-1), Gro-alpha (Gro- $\alpha$ ), vascular endothelial growth factor (VEGF) and IL-10 were quantified using a Luminex $^{\mathrm{TM}} 200$ instrument (Millipore, Billerica, MA) by monitoring the fluorescence associated with the different bead sets. Total rat TGF- $\beta$ expression was determined using an immunosorbent enzyme-linked assay (ELISA) kit, according to the manufacturer's instructions (eBioscience, Carlsbad, CA).

\subsection{Statistical analysis}

Statistical analysis was performed using GraphPad Prism 5 (GraphPad Software, La Jolla, CA). A Kolmogorov-Smirnov test was performed to ascertain the normality of the distributed data.
For neutrophil quantification and angiogenesis-related assays, a one-way ANOVA, followed by a Newman-Keuls comparison post-test was conducted. Statistical analysis of wound closure was performed with a two-way ANOVA, followed by a Bonferroni comparison post-test. For antioxidant enzymes activities and cytokine expression, a Kruskal-Wallis test, followed by Dunn's Multiple Comparison post-test was used. A 95\% confidence interval was considered as statistical significant.

\section{Results}

\subsection{Mechanisms of dextrin-LLKKK18 conjugate production}

Dextrin-LLKKK18 conjugates were obtained after conjugation of a free amine in the peptide with a carboxyl group created in the dextrin backbone through succinoylation (Fig. 1A). FT-IR spectra confirmed the successful succinoylation of dextrin (Fig. SI-1A). Indeed, succinoylated dextrin spectrum showed a transmittance peak around $1730 \mathrm{~cm}^{-1}$, which was absent in the unmodified dextrin and that is typical for the ester groups inserted in the dextrin backbone [22]. Characteristic peaks of dextrin were also present in both conditions at about $3390 \mathrm{~cm}^{-1}(\mathrm{OH})$ and $2927 \mathrm{~cm}^{-1}\left(\mathrm{CH}, \mathrm{CH}_{2}\right)$.

A modified dextrin with $8.8 \% \mathrm{~mol}$ succinoylation was used to conjugate LLKKK18 and the reaction resulted in the binding of $\sim 50 \%$ of the initial peptide added. In vitro degradation of succinoylated dextrin and its peptide conjugates occurred at a much slower pace than that of the non-activated dextrin (Fig. SI-1B). This is important for a slow, sustained release of LLKKK18 upon contact with amylases in the wounds. Peptide conjugation did not further hinder the degradation of the functionalized dextrin. Also, the release of the conjugates from the hydrogel was performed in a system simulating the wound surface environment, using a Transwell chamber. As depicted in Fig. SI-1C the peptide present in the Carbopol ${ }^{\circledR}$ hydrogel underwent an initial burst release up to $\sim 35 \%$ during the first 2 days but then declined to a slower release up to day 35 .

Since peptide conjugation may result in the loss of its activity, we have also evaluated the antimicrobial activity of LLKKK18. As shown in Fig. SI-2, LLKKK18 inhibited the growth of Escherichia coli strain $\mathrm{K} 12$ in a dose-dependent manner, with a concentration of $0.35 \pm 0.01 \mu \mathrm{M}$ leading to a growth reduction of $50 \%$. The conjugation with dextrin masked this antimicrobial activity, as the peptide's $\mathrm{IC}_{50}$ was calculated to be $1.77 \pm 0.25 \mu \mathrm{M}$. However, the incubation of the conjugates for $1 \mathrm{~h}$ with amylase prior to the assay reinstated the antimicrobial activity of LLKKK18, which showed an $\mathrm{IC}_{50}$ of $0.48 \pm 0.03 \mu \mathrm{M}$.

\subsection{Burn wound improvement by treatment with LLKKK18}

General morphology of the wounds treated with conjugate-containing or blank hydrogels was evaluated over time in the rat burn model shown in Fig. 2. Briefly, we shaved the hair from the rats' dorso (Fig. $2 \mathrm{~A}$ ) and created $1.5 \mathrm{~cm}$ diameter partial thickness burn wounds by pressing a brass cylinder heated at $80^{\circ} \mathrm{C}$ against the rats shaved skin (Fig. $2 \mathrm{~B}$ and C). We then applied the conjugate-loaded or blank hydrogels on top of the wounds every 3 days (Fig. 2D).

Macroscopic analysis of the wounds showed the healing progression after the treatments were administered (Fig. 3A). A faster reduction in wound size was observed in the presence of LLKKK18, particularly up to day 12 . After 18 days full wound closure was attained for treatments containing Carbopol ${ }^{\circledR}$. In accordance with the qualitative analysis, quantitative evaluation of wound closure showed that the peptide accelerated the wound healing process, as a significant decrease in wound area was observed at days 6 

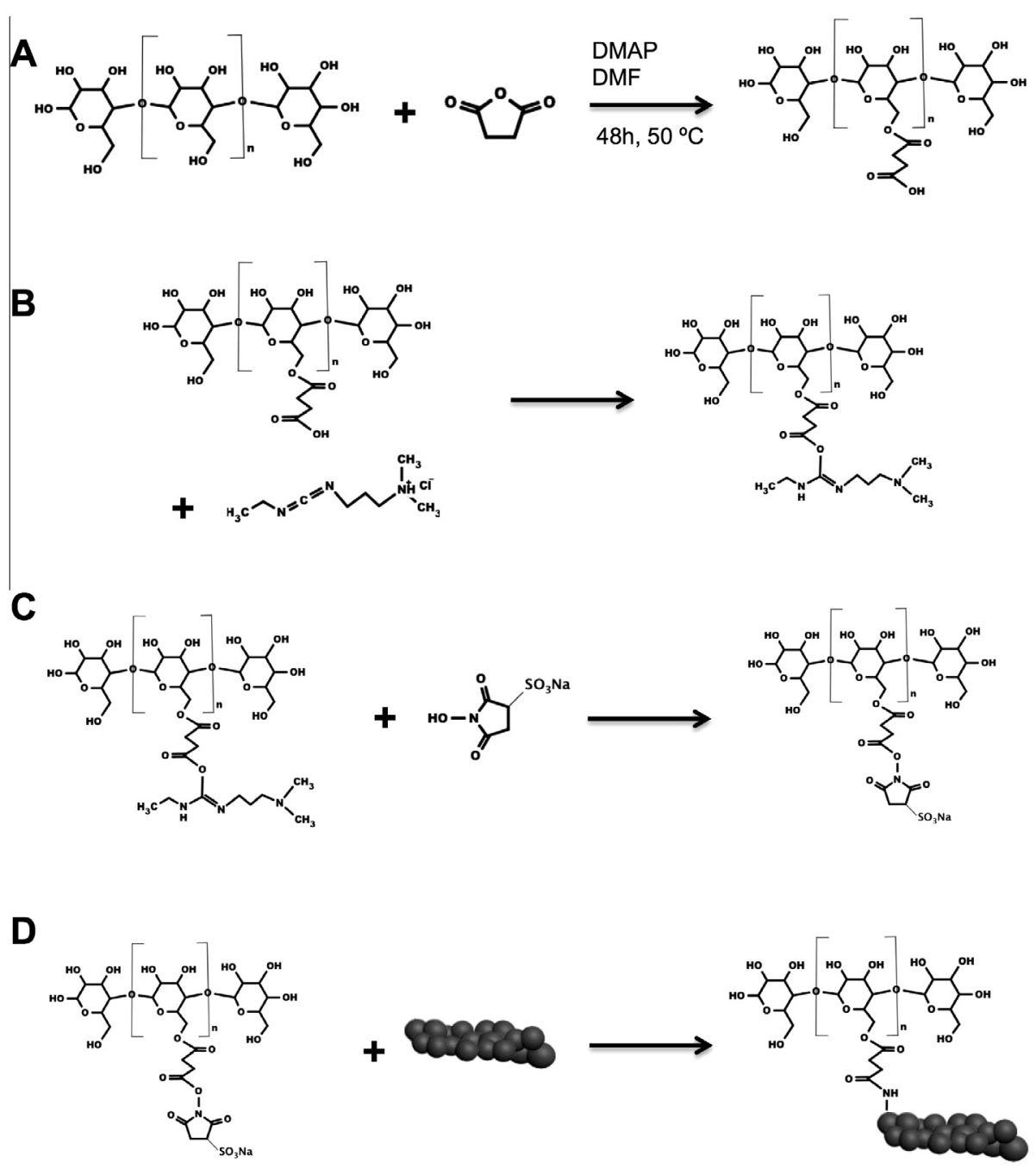

Fig. 1. Schematics of the formation of Dextrin-LLKKK18 conjugates. (A) Dextrin was modified by reacting it with succinic anhydride in the presence of DMAP and DMF, at $50{ }^{\circ} \mathrm{C}$ for $48 \mathrm{~h}$. (B) Succinoylated dextrin then reacts with EDC, forming an amine-reactive $O$-acylisourea intermediate, (C) which reacts with NHS to form an amine-reactive NHS ester. (D) Finally, free amines within LLKKK18 bound to the modified dextrin through stable amide bonds.

and 12 , in comparison with control wounds (Fig. 3B). Noteworthy, the PBS-treated wounds, took longer to fully close than the hydrogel-treated ones. Also, it should be noted that the succinoylated dextrin alone embedded in Carbopol $^{\circledR}$ did not influence wound healing. This is in accordance with Hardwicke and colleagues [22], who have previously demonstrated the healing inability of succinoylated dextrin alone in a chronic wound model. Therefore, the difference in the speed of wound recovery may only be attributed to the peptide. By day 18 no significant differences in wound size were observed between treated and non-treated wounds.

In general, re-epithelialization with a well-defined epidermis occurred with Carbopol ${ }^{\circledR}$ alone and conjugate-containing treatments, as shown in the cross-sections from the wound tissues at day 18 post-burn (Fig. 4A). Indeed, higher magnification of the sections further confirmed the good organization of these structures (Fig. 4B). Moreover, when compared to control wounds, LLKKK18-treated wounds showed a higher content of collagen well organized in fibrils as shown by the higher amount of the blue color due to the Masson's Trichrome staining (Fig. 4A and B).

Overall, these results indicated that this hydrogel system, and in particular LLKKK18, is able to accelerate the burn healing process, as well as to improve the quality of the newly formed tissue.

\subsection{Regulation of the redox state in the burn wounds by LLKKK18}

High intracellular levels of reactive oxygen species (ROS), which occur during the initial stages post-burn, have been often described in the literature as inducers of oxidative damage. Nonetheless, their deleterious effects depend on their balance with the natural antioxidants of the cells and, at lower levels, ROS can actually function as second messengers, playing an important role in the activation of signaling pathways responsible for stimulation of wound healing [28].

Superoxide dismutase (SOD) acts as the first line of defense against superoxide anions $\left(\mathrm{O}^{-}{ }^{-}\right)$, by dismutating these anions to hydrogen peroxide [29]. Indeed, SOD activity increased right after the burn is made (Fig. 5A). However, this activity then decreased significantly during the first $24 \mathrm{~h}$ in the LLKKK18-treated wounds when compared with carbopol-treated wounds. Although SOD activity was maintained at normal skin levels in both conditions between days 3 and 6 , a significant increase was observed in the LLKKK18-treated wounds by day 9 .

Also immediately after the burn, hydrogen peroxide concentration was increased. Both treatments induced a decrease in $\mathrm{H}_{2} \mathrm{O}_{2}$ levels after $24 \mathrm{~h}$ (Fig. 5B). Whereas in the Carbopol ${ }^{\circledR}$-treated wounds $\mathrm{H}_{2} \mathrm{O}_{2}$ concentration then stabilized at normal skin values, in the presence of LLKKK18 $\mathrm{H}_{2} \mathrm{O}_{2}$ was decreased to lower levels 

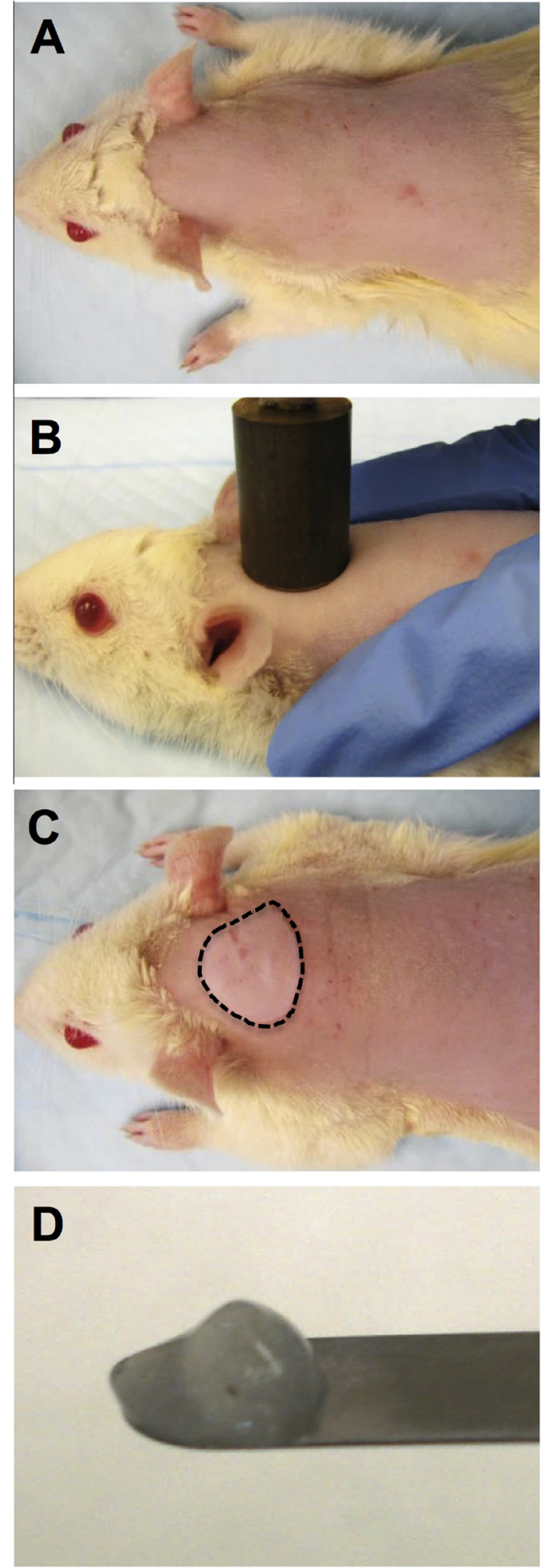

Fig. 2. Partial-thickness rat burn wound model. (A) Hair from Sprague-Dawley rats' dorsum was removed and (B) a brass cylinder heated at $80^{\circ} \mathrm{C}$ was used to create (C) identical burns on the backs of the rats. (D) About $250 \mu$ l of a Carbopol ${ }^{\circledR}$ hydrogel on a spatula ready to be applied on top of the burned tissue.

than the Carbopol ${ }^{\circledR}$ control between days 3 and 6 . However, the concentration of $\mathrm{H}_{2} \mathrm{O}_{2}$ rose again to significantly high levels at 9 days post-burn paralleling the increase in SOD levels.
There are two antioxidant enzymes, catalase and glutathione peroxidase (GPX), which come into play to remove the excess of $\mathrm{H}_{2} \mathrm{O}_{2}$. A decrease in the activity of GPx was observed for both LLKKK18-treated and non-treated conditions after $24 \mathrm{~h}$. Carbopol $^{\circledR}$ treatment then resulted in the stabilization of catalase activity at normal skin levels up to day 9 post-burn. Similar levels were observed after LLKKK18 treatment but only up to day 6. After this time the peptide induced an increase in catalase when compared to Carbopol ${ }^{\circledR}$-treated control reaching a threefold increase at day 9 (Fig. 5C). GPx activity decreased significantly compared with the Carbopol ${ }^{\circledR}$-treated control for the first $24 \mathrm{~h}$ but then started to increase to reach the levels of the control wounds at 3 days post-burn and stabilized at high levels between days 6 and 9 (Fig. 5D).

ROS are highly reactive and can cause damage to biologically relevant macromolecules like DNA, lipids and proteins [30]. DNA damage was evaluated by the measurement of 8-OH-dG levels in the tissues. Despite a slight increase in oxidative DNA damage $1 \mathrm{~h}$ after the burn $(p<0.05)$, no significant differences were observed between LLKKK18-treated and Carbopol ${ }^{\circledR}$-treated wounds up to 9 days post-burn. Lipid peroxidation, as indicated by MDA levels in the tissue, did not undergo any significant differences in the Carbopol ${ }^{\circledR}$-treated wounds until day 6 , rising only by day 9 post burn (Fig. 5E). A similar trend was observed when wounds were treated with LLKKK18, although MDA concentration in this case was significantly lower than the control throughout the nine days of the study. Interestingly, during the first 6 days undergoing peptide treatment lipid peroxidation levels were practically negligible (Fig. 5F). Regarding protein nitration, indicated by nitrotyrosine concentration in the tissues, no initial differences were observed between burn and normal skin (Fig. 5G). Also, no variations were observed in the control wounds up to day 6 . Nevertheless, at this time protein nitration levels were significantly lower in the LLKKK18-treated wounds. Similarly to what occurred for lipid peroxidation, an increase in nitrotyrosine levels was detected at day 9. However, no statistically significant differences were observed between the Carbopol ${ }^{\circledR}$-treated and peptide-treated wounds (Fig. 5G).

These results indicate that LLKKK18 reduced the initial levels of oxidative stress to some extent, potentially preventing ROS damaging effects during the first days post-burn.

\subsection{LLKKK18 stimulates the development of new blood vessels}

Development of new blood vessels during the healing of the burned tissue was assessed by immunolabeling the tissue sections for $\alpha$-smooth muscle actin ( $\alpha$-SMA), a protein present in the smooth muscle cells surrounding the microvessels [31]. The angiogenic process in response to injury is important to promote a more effective transport of nutrients and cytokines to the wound site. Treatment with LLKKK18 resulted in approximately 3-fold increase in the number of new blood vessels that developed in the tissue (Fig. 6A and B). However, no differences were observed between treatments in blood vessel width or area (Fig. 6C and D). To confirm that this peptide is angiogenic we performed injections with LLKKK1 8 under the skin of C57Bl/6 mice during 4 consecutive days. Mouse tissues collected from the injection sites displayed a significantly larger blood vessel network (about 1.5-fold, $p<0.01$ ), compared to PBS alone (Fig. SI-3A and B). VE-cadherin, also known as CD144, is localized at the adherens junctions that old the endothelial cells together. Immunoblot analysis for this molecule showed a 1.85 -fold increase in VE-cadherin levels in LLKKK18 treated tissues ( $p<0.01$, compared to control), indicating that the microvessels were tighter and potentially more stable in the presence of the peptide (Fig. SI-3C). 



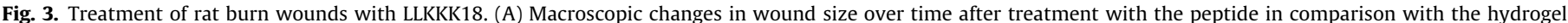

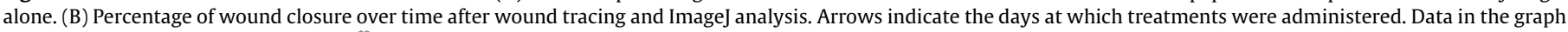
represent the mean \pm S.D. for an $n=6$. ${ }^{* *} p<0.01$, compared to carbopol.

\subsection{Inflammation regulatory role of LLKKK18}

After burn injury, inflammatory cells are recruited to the wound site, initiating the inflammatory stage of the healing process, which is characterized by the sequential infiltration of neutrophils and macrophages [32]. The presence of these cells in the burn wound tissue was evaluated after treatment with LLKKK18.

Neutrophils play a protective antimicrobial role, eliminating invading microbes, as well as damaged and denatured extracellular matrix components from the wound site [33]. However, proteases and ROS released by these cells may also result in some additional damage [32]. Neutrophils were identified with MPO-staining, characteristic of granulocytes (Fig. 7A). The insert in this figure shows the presence of the MPO-containing granules. Treatment with LLKKK18 resulted in reduced neutrophil response in day 1 comparing to carbopol-treated wounds (Fig. 7B). This suggests that the peptide down-regulates the acute inflammatory reaction.

Macrophages play several roles during the healing process. Early after the wound is inflicted, they further promote the inflammatory response by releasing cytokines that recruit additional leukocytes [32]. In addition, they are involved in the clearance of apoptotic neutrophils from the wound a few days post-injury, beginning the decline of inflammation [34]. As macrophages clear the tissue from these apoptotic cells they change their phenotype to a reparative state, with subsequent release of molecules that stimulate the migration of fibroblasts, epithelial and vascular endothelial cells into the wound, setting the stage for tissue remodeling [32].

The presence of macrophages in the burn tissues was evaluated by flow cytometry. The rationale for differentiating macrophage phenotype is shown in Fig. SI-4. Doublets were discriminated from single cells by plotting FSC-H vs FSC-A. Then live cells were gated and from that positive and negative gates were defined to distinguish between M1 and M2 skewed macrophages. Patterns of macrophage recruitment differed between Carbopol $^{\circledR}{ }_{-}$and LLKKK18-treated wounds (Fig. SI-5). Initially, a higher M1 macrophage recruitment occurred in Carbopol-treated wounds compared to LLKKK18 (Fig. SI-5). Indeed, the lower M1 influx after peptide treatment correlated with the lower oxidative stress levels and decreased damage observed. Moreover, an earlier M2 macrophage recruitment was observed in the LLKKK18-treated wounds (day 6 vs day 12, for peptide and carbopol-treated, respectively), as depicted in Fig. SI-5. This higher M2 macrophages influx might have also contributed to the lower inflammatory response observed in the presence of the peptide. 

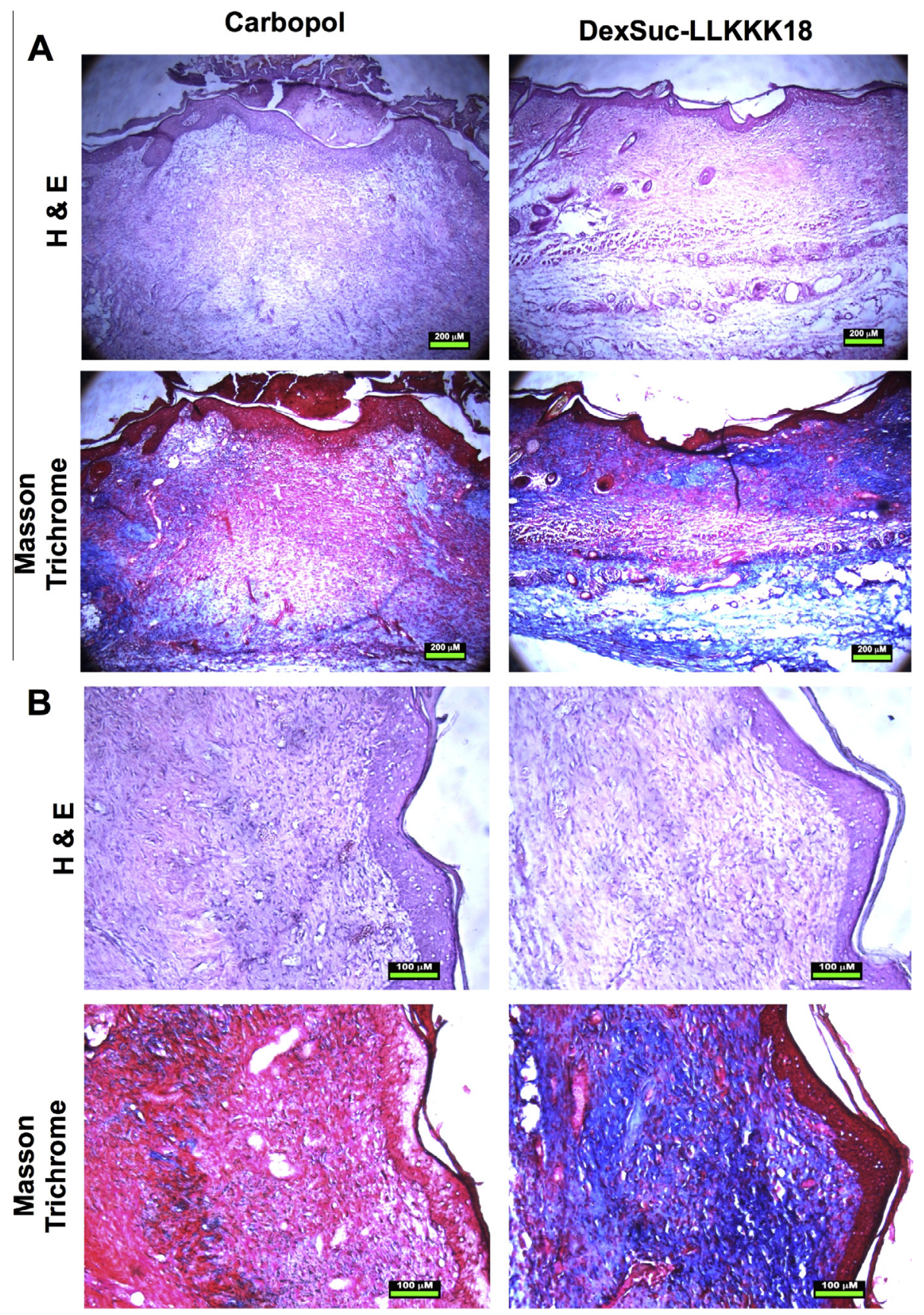

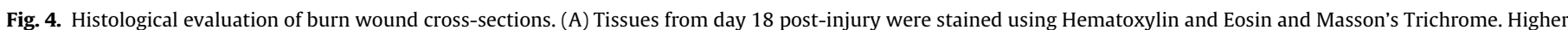

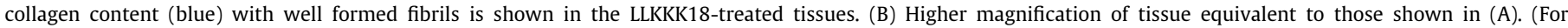
interpretation of the references to color in this figure legend, the reader is referred to the web version of this article.)

The potential mechanism involved in the modulation of inflammation by the LLKKK18 released from the conjugates was further studied by evaluating the levels of the chemokines Growth regulated oncogene-alpha (Gro- $\alpha$ ) and monocyte chemoattractant protein-1 (MCP-1) because they are chemotactic for neutrophils and monocytes, respectively (Fig. 8A). LLKKK18 significantly decreased Gro- $\alpha$ during the first 3 days after wounding. Thereafter, the levels of this chemokine were very similar to those in Carbopol $^{\circledR}$-treated controls. This is consistent with the neutrophil immunolabeling results, which showed much less staining for neutrophils in the LLKKK18-treated wounds during the first 3 days after injury (Fig. 7A and B).
MCP-1, one of the chemokines involved in infiltration of monocytes into the wound tissue that go on to differentiate into macrophages, was decreased on day 3 (Fig. 8B). Notably, at day 3 it was significantly lower in LLKKK18-treated wounds and remained at these very low levels up to day 12 .

Vascular endothelial growth factor (VEGF) is a signal protein involved in several biological processes, from inflammation to angiogenesis [35]. In our burn model VEGF concentration gradually increased until it reached a peak by day 6 , in both conditions. At this time is when the microvessels in the burn tissue are developing at high levels. Moreover, between days 3 and 9, VEGF levels were significantly higher in the tissues treated with LLKKK18 

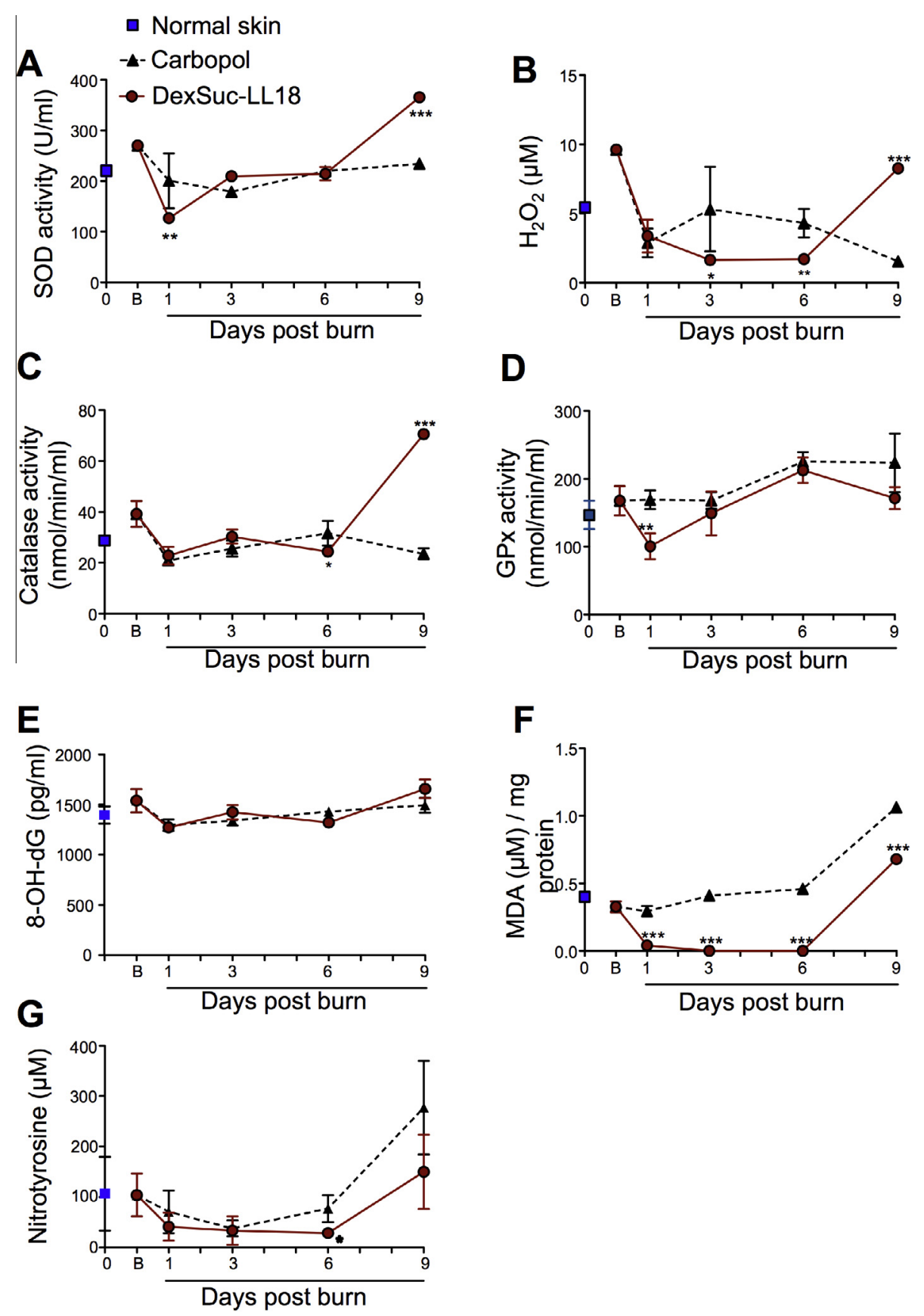

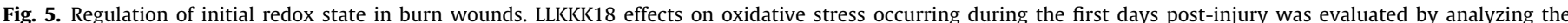

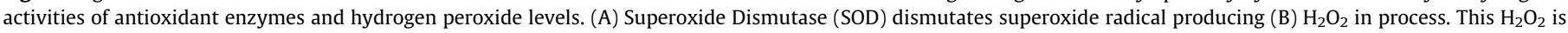

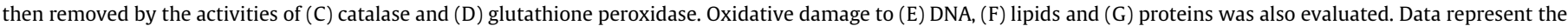
mean \pm S.D. of at least three independent experiments. $p<0.05,{ }^{* * *} p<0.01,{ }^{* * *} p<0.001$, compared to carbopol. B = Burn skin.

compared to those treated with Carbopol ${ }^{\circledR}$ alone (Fig. 8C). This pattern of high levels of VEGF in peptide-treated burn wound tissue correlated well with its ability to increase angiogenesis (Fig. 6).

The concentration of interleukin-10 (IL-10), an anti-inflammatory cytokine, was decreased in the burned skin $1 \mathrm{~h}$ after the burn was made (Fig. 8D). It has been shown that IL-10 levels increase during the early stages of burn wound response, followed by its return to baseline levels around day 7 [36]. We also found that LLKKK18 significantly increased the levels of IL-10 early post wounding when compared with the Carbopol ${ }^{\circledR}$ treatment that caused the increase at day 6 . These data support the beneficial role of the peptide on an early IL-10 response, which is known to help resolve the inflammatory response post-injury [37].

Transforming growth factor-beta (TGF- $\beta$ ) is another cytokine involved in different signaling mechanisms, including inflammation, cell proliferation, differentiation, scarring and tissue remodeling [38]. The levels of this cytokine go up-and-down throughout the wound healing process, with a similar profile between peptide and control-treated groups (Fig. 8E). Major differences were observed at days 1 and 18 . Indeed, at day 1 , while TGF- $\beta$ increased in the control group to higher values than the ones observed $1 \mathrm{~h}$ post-burn, LLKKK18-treated tissues showed significant decrease with levels 

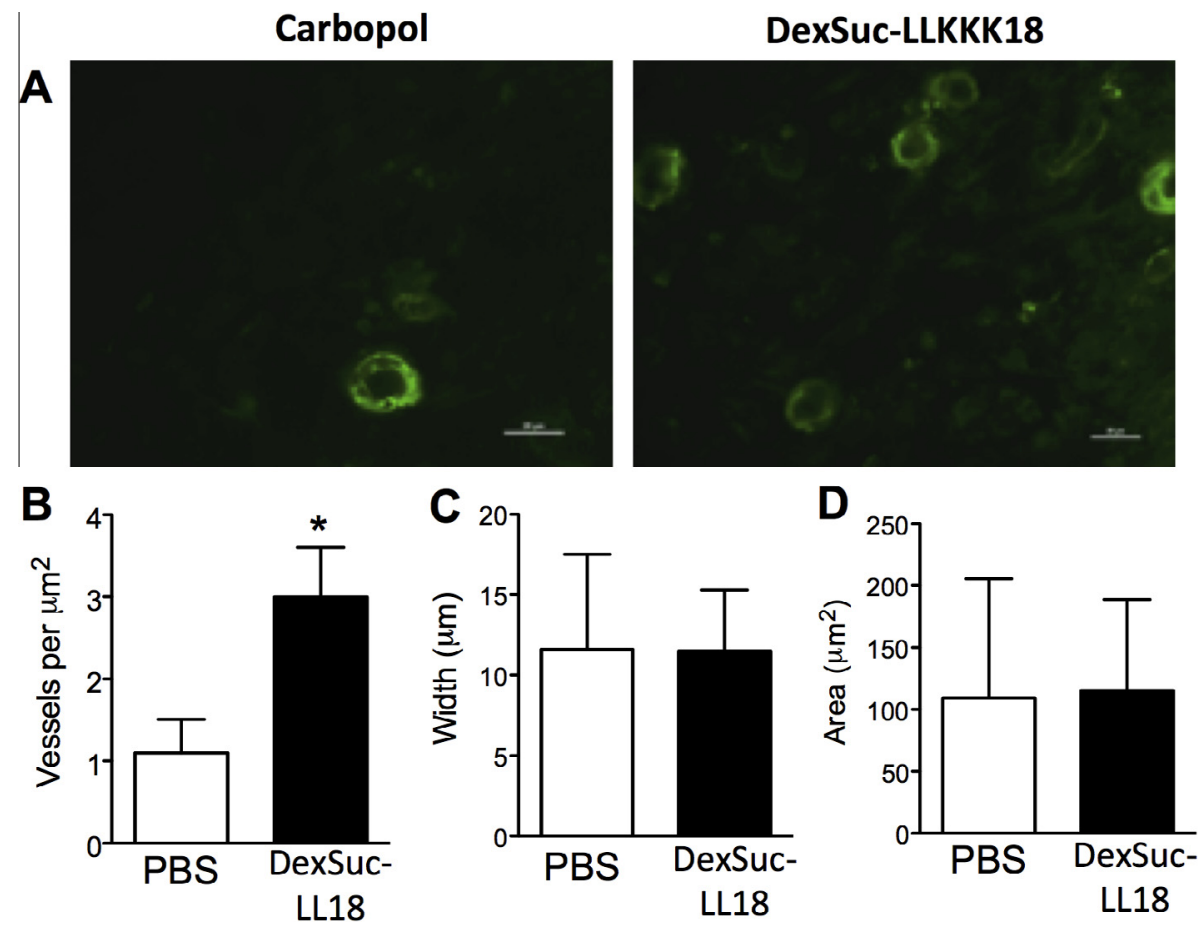

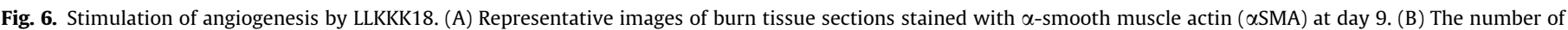

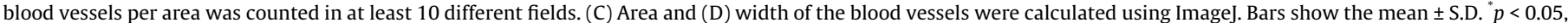
compared to carbopol.
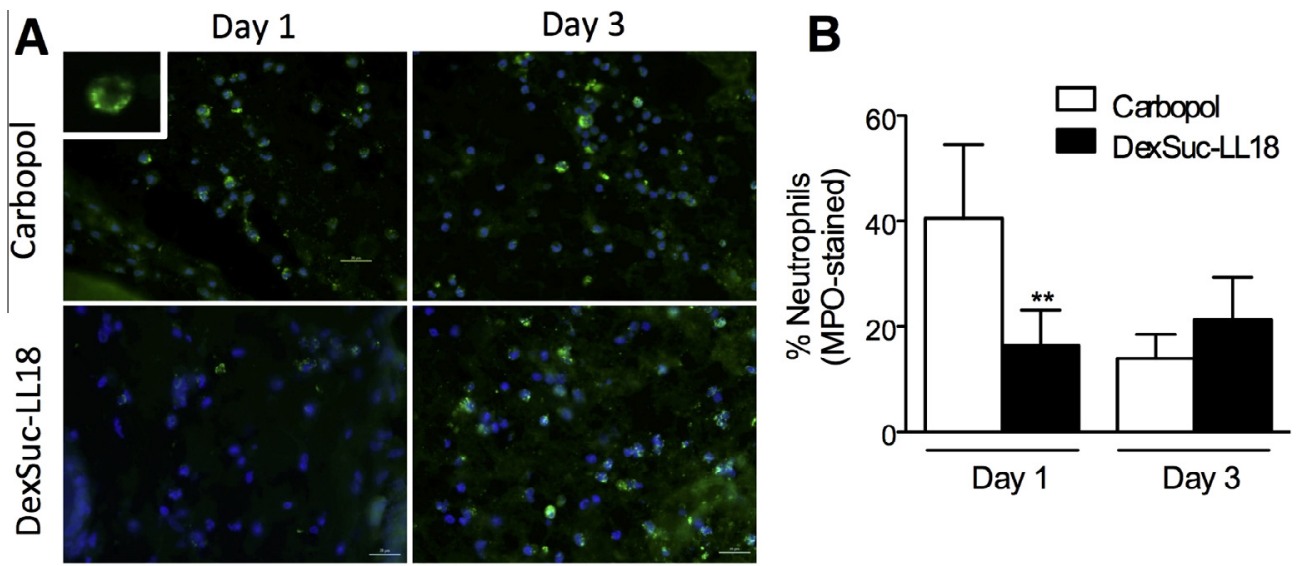

Green - Myeloperoxidase

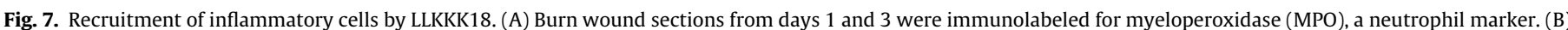

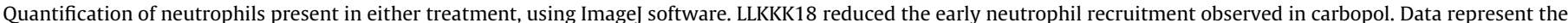
mean \pm S.D. of at least three independent experiments. ${ }^{* *} p<0.01$, compared to carbopol.

similar to the normal skin. The opposite occurred at day 18 , as the concentration of TGF- $\beta$ present in the tissues was significantly elevated in the tissues treated with the peptide (Fig. 8E).

\section{Discussion}

Burns represent a devastating form of trauma, involving severe pain, distress and decrease of life quality for many patients worldwide. Indeed, thermal injury can severely compromise the skin barrier, affecting important functions such as body fluid homeostasis, thermoregulation and protection against infection $[39,40]$. Hydrogels were shown to induce faster healing of partial-thickness burn wounds, since they maintain a moist environment, as well as contribute to wound debridement by rehydration of non-viable tissue $[5,41]$.

In this work we conjugated LLKKK18 with dextrin, protecting the peptide from being readily degraded in the harsh burn tissue environment, while allowing its sustained release over time, because exposure of dextrin to the high concentration of wounds $\alpha$-amylases [42] results in its backbone degradation, with subsequent peptide release. A degree of dextrin modification of $8.8 \%$ mol was sufficient to delay degradation of this molecule by $\alpha$-amylase. Moreover, the incorporation of the conjugates into Carbopol ${ }^{\circledR}$ hydrogels presented several advantages, as not only it provided the required moist environment to the wound site, it also performed as a carrier for the topical application of the conjugates. 

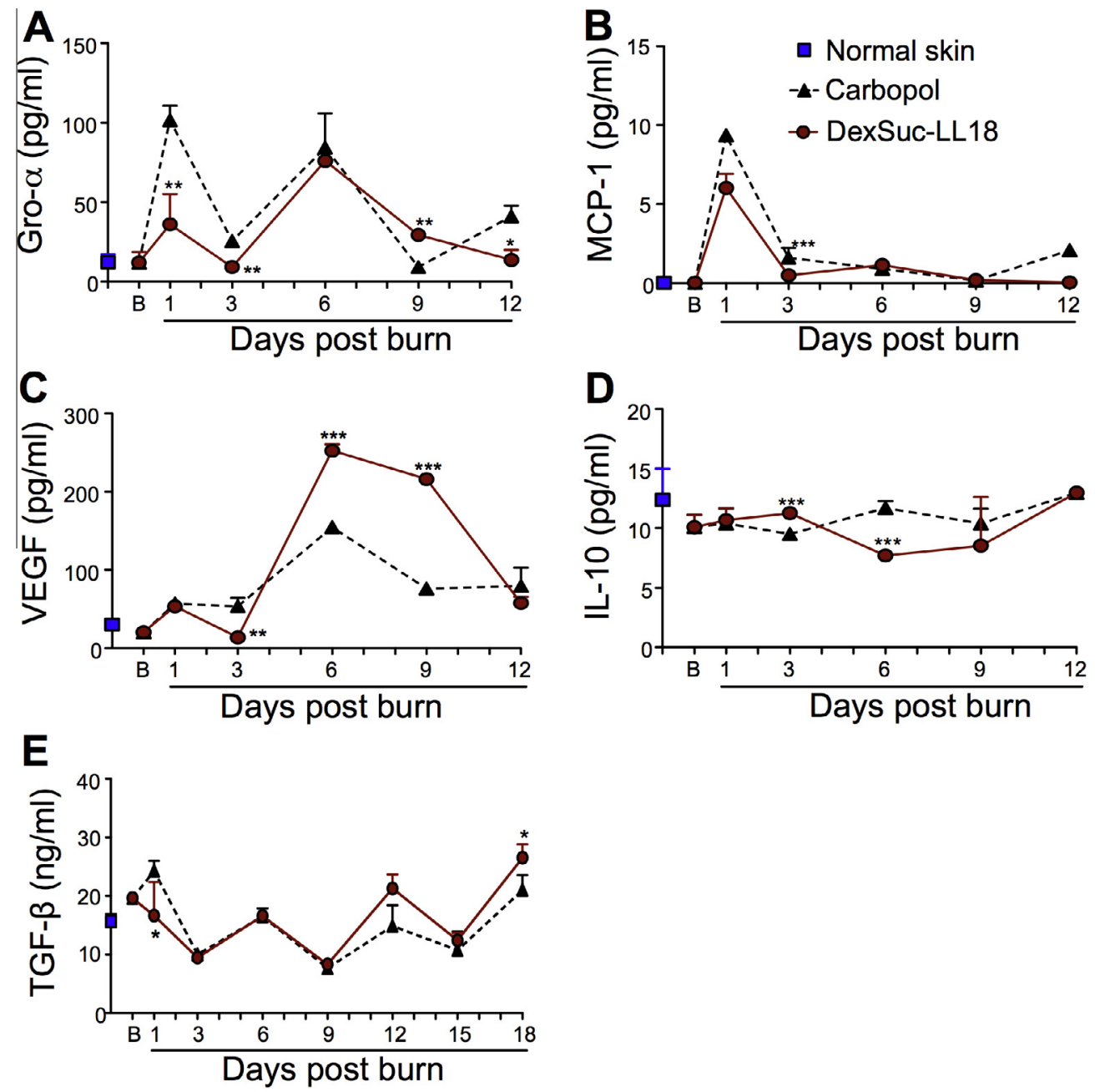

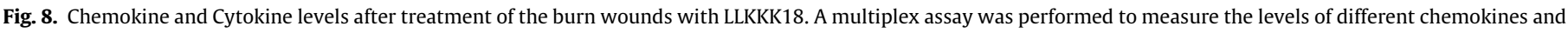

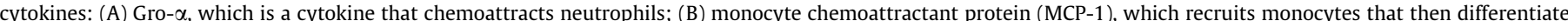

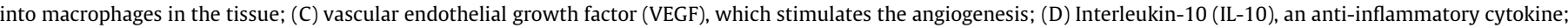

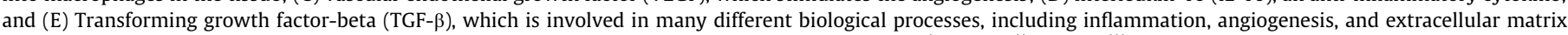
production and deposition. TGF- $\beta$ levels in the homogenates were determined using an ELISA assay. ${ }^{*} p<0.05,{ }^{* *} p<0.01,{ }^{* * *} p<0.001$, compared to carbopol. B $=$ Burn skin.

In addition, it contributed to a slow release of the conjugates over time leading to sparser change of the dressing.

Antimicrobial properties against different strains, including E. coli and Staphylococcus aureus have been previously attributed to LLKKK18 [15,16]. Also, we have recently reported this peptide's ability to reduce Mycobacterium avium's growth [43]. In this work, we determined its antimicrobial activity against the $E$. coli strain K12 and observed that when conjugated with dextrin, LLKKK18 has its activity decreased, in agreement with what has been previously reported for other molecules [22]. However, after degradation of the conjugates by amylase, which can also be found at wound sites, the antimicrobial activity of LLKKK18 was restored.

Although the involvement of the human cathelicidin LL37 in wound healing has already been described [14], its effects on the wound healing processes, as well as the mechanisms of action of the modified analogue LLKKK18 are still unknown. As we show here, the peptide released from the conjugates, when compared to the controls treated with hydrogel, helped accelerate the healing process as well as contributing to proper collagen deposition, with better fiber formation, in the granulation tissue.

Burns trigger a myriad of systemic responses, including an increased metabolic rate, elevated energy expenditure, faster breakdown of proteins, lipids and polysaccharides, immunodeficiency and delayed wound healing, which are mainly mediated by high doses of ROS and activated neutrophils [44,45]. We showed that LLKKK18 reduced this initial oxidative burden, as indicated by lower levels of $\mathrm{H}_{2} \mathrm{O}_{2}$ and antioxidant enzymes (in particular SOD and GPX) as well as by a lowered recruitment of neutrophils to the burn tissue. Indeed, Gro- $\alpha$, a neutrophil chemoattractant cytokine, was present at lower levels during the first 3 days in LLKKK18-treated burns. Also, immunostaining showed a much lower number of neutrophils in the LLKKK18-treated wounds in the first day. As a result of reduced oxidative stress, damage to major cellular biomolecules, in particular lipids, was also decreased in the presence of LLKKK18, compared to the hydrogel alone.

Moreover, the overall reduction of the initial oxidative stress in the presence of the peptide is of major importance as it can help achieve faster wound recovery and tissue repair. Indeed, it has been reported that at concentrations below those required to cause oxidative damage, ROS may regulate intracellular signal transduction pathways through redox-dependent mechanisms, including vascular smooth muscle cell growth and migration, modulation of endothelial function and modification of the extracellular matrix [46]. On the other hand, the imbalance between oxidants and antioxidants in favor of the former has been reported as one factor resulting in the entrapment of wounds in the inflammatory stage [33]. 
An unexpected increase in oxidative stress was observed at day 9, following a significant increase in SOD and $\mathrm{H}_{2} \mathrm{O}_{2}$ levels. However, no significant damage was induced to DNA, lipids or proteins, which may be related to the increase in catalase activity, counteracting $\mathrm{H}_{2} \mathrm{O}_{2}$ production by converting it into water. Regarding GPx activity, a similar trend was observed between LLKKK18- and hydrogel-treated wounds over time, suggesting little or no influence of the peptide on this antioxidant enzyme's activity.

Oxidation reactions have for a long time been implicated in collagen crosslinking in the presence of high glucose concentration [47]. A study conducted by Elgawish and colleagues [48] provided evidence for a key role played by $\mathrm{H}_{2} \mathrm{O}_{2}$ in collagen cross-linking and thermal stability in vivo. The authors followed tissue glycation kinetics in tendons implanted in diabetic rats and concluded that faster glycoxidation and crosslinking occurred 30 days after diabetes onset, i.e. by the time high tissue glycation was detected. However, when catalase or other antioxidants were injected, collagen crosslinking was suppressed. High energy expenditure observed in burns has also been reported to increase glycogenolysis with a subsequent enhanced glucose production that results in a hyperglycemic state [49]. In this sense, it is reasonable to consider that the LLKKK18-induced hydrogen peroxide formation in burn wounds at day 9 may actually be accelerating collagen crosslinking, thus contributing for a faster remodeling of the extracellular matrix.

Angiogenesis, the formation of new blood vessels from pre-existing ones, is a key factor for proper burn wound healing, as the increased metabolic rate observed in such wounds demands the rapid and efficient transport of nutrients, inflammatory cells, cytokines and chemokines to the wound site [50]. Although pro-angiogenic properties have already been attributed to LL37 [14], no data had been reported on the ability of LLKKK18, a similar but smaller peptide, to induce angiogenesis. This peptide is also more cationic and hydrophobic than LL37, with clear implications in attaining higher antimicrobial and chemoattractant activity than its analogue [15]. Moreover, its smaller size is advantageous as not only facilitates its transport across cell membranes but also costs less to synthesize. Here we showed the clear pro-angiogenic effect of LLKKK18 in vivo, as it induced a threefold increase in the density of newly formed microvessels, compared to the hydrogel alone. This property was further confirmed in a mouse model. Similarly to the findings in the rat model, a pronounced angiogenic effect was observed in the presence of LLKKK18. Furthermore, because sometimes the new vessels are leaky, thus hampering the transport of substances to the wound site and increasing edema [38], we quantified the levels of vascular endothelial cadherin (VE-cadherin), a protein involved in the regulation of vascular permeability and vessel tightness [51]. The expression of VE-cadherin was increased in the presence of LLKKK18, indicating that this peptide improved the integrity and stability of the newly formed microvessels.

An inflammatory response develops in the burn tissue during the first few days post-injury, initiating cell migration and proliferation, as well as clearance of cell debris [33]. Importantly, moisture balance, as the one provided by the hydrogel, has been reported as critical for healing, because the moist environment facilitates the action of growth factors, cytokines and chemokines [4]. Nevertheless, successful repair of damaged tissue requires the resolution of the inflammatory response, as a prolonged inflammatory phase has been described to result in postponed, incomplete or uncoordinated healing process that may ultimately lead to a chronic wound [32,52].

LLKKK18 released from the dextrin-conjugates stimulated a lower inflammatory response than the Carbopol ${ }^{\circledR}$ hydrogel alone during the initial days post-injury. In addition to the decrease in
Gro- $\alpha$ and in neutrophil numbers, lower concentration of MCP-1 was detected. MCP-1 is a pro-inflammatory cytokine known to recruit monocytes that differentiate into macrophages in the wound site. Macrophages can easily adapt to different biological functions due to their plasticity, switching phenotype according to the surrounding signals. Broadly, and depending on the activation pathway, macrophages can be M1 type (classically-activated) or M2 type (alternatively-activated) macrophages. M1 macrophages, which are induced by LPS or IFN- $\gamma$, are characterized as pro-inflammatory and elicit a type 1 response. On the other hand, M2 macrophages elicit an anti-inflammatory response stimulated by IL-4, IL-13 or IL-10 [53]. Our data show that treatment with LLKKK18 results in early recruitment of M2 macrophages, suggesting a faster resolution of the inflammatory stage and a potential regulation of angiogenesis through M2 macrophage skewing. Indeed, it has been shown that M2 macrophages have a higher angiogenic potential compared to other subsets [54]. Consistent with these findings, levels of IL-10, known to be released mainly by M2 macrophages, were also increased in the presence of LLKKK18 during the first few days post-injury. IL-10 is an anti-inflammatory cytokine whose major influence on the polarization of macrophages and their ability to regulate angiogenesis has already been previously reported [55]. After an initial stage of healing in which the main concern is to avoid propagation of damage, wound mediators and inflammatory cells start being recruited to the wound site, preparing the tissue for proliferation and remodeling. As a result, the wound starts to close and a reduction in wound area may occur. In agreement with this, the early increase in IL-10 levels, accompanied by the earlier recruitment of M2 macrophages, observed in the peptide-treated wounds, coincides with a significant reduction of wound area at day 6. Moreover, it should also be noted that a prolonged inflammatory stage might turn a wound into chronic. Interestingly, we observed that while anti-inflammatory cytokines and macrophages were earlier stimulated, pro-inflammatory molecules like Gro- $\alpha$ and MCP-1 were maintained at low levels after the first days post-wound.

In addition, the concentration of VEGF rose almost at the same time in the LLKKK18-treated wounds. VEGF has been described as one of the most important stimulators of angiogenesis and vasopermeability, and is produced by macrophages as a result of the burn hypoxic environment to stimulate endothelial cells migration and proliferation [35,56]. Indeed, this increase in VEGF levels coincided with a faster decrease of the wound area (Fig. 3B), suggesting the importance of angiogenesis stimulation by LLKKK18 to the overall acceleration of wound healing, mainly observed at days 6 and 12 .

The increase in M1 macrophages that occurred at day 9 in LLKKK18-treated wounds may be related to the augmented $\mathrm{H}_{2} \mathrm{O}_{2}$ concentration. Indeed, it has been reported that $\mathrm{H}_{2} \mathrm{O}_{2}$ modulates expression of leukocyte and endothelial adhesion molecules adhesion [28]. Nevertheless, this $\mathrm{H}_{2} \mathrm{O}_{2}$ increase at day 9 may help explain the stall in healing, as it may result in a temporary increase in oxidative stress.

TGF- $\beta$ participates in different cellular functions, including inflammation, stimulation of angiogenesis, collagen synthesis and tissue remodeling [38,57]. Its involvement in these processes could, at least partially, explain the up-and-down regulation of this cytokine, which we observed during wound healing progression. Wang and colleagues [58] have reported the rapid up-regulation of TGF- $\beta$ after injury, suggesting it to be responsible for the initiation of inflammation, together with other cytokines, such as MCP-1, and formation of granulation tissue. Indeed, we noticed an initial increase in TGF- $\beta$ in the control wounds. However, LLKKK18 kept this cytokine at normal skin levels, further confirming the lowered inflammatory response elicited by this peptide. Moreover, the enhanced TGF- $\beta$ expression observed at 18 days post 
burn raises some concern that while healing the wound faster, LLKKK18 may have some scarring effects. However, it may also be related to the role played by TGF- $\beta$ in tissue remodeling. Indeed, it has been known for some time that TGF- $\beta$ released from inflammatory cells stimulates fibroblasts to contract the wound matrix [59] and for stimulating collagen and fibronectin production, thus strengthening the wound tissue [58].

\section{Conclusions}

LLKKK18 released from dextrin conjugates incorporated in Carbopol ${ }^{\circledR}$ hydrogels accelerates the healing process and improves the tissue quality of burn wounds. This was achieved through regulation of initial oxidative stress and inflammation. Also important, it induces a faster resolution of the inflammatory phase by recruiting M2 macrophages early post-injury. Moreover, it stimulates angiogenesis in the granulation tissue, which is of utmost relevance to attain the rapid transport of growth factors, cytokines and chemokines to the wound site, thus contributing to a faster wound healing with proper tissue organization.

In this sense, this work presents a new, safe, inexpensive and effective formulation for the treatment of burn wounds, which is easy to apply and remove, maintains a moist environment and with the potential to keep the wound site free from infections due to the presence of an antimicrobial peptide. Therefore, this delivery system has great potential as a therapeutic approach for burn wound treatment. Nevertheless, further experiments still have to be performed before taking it to the clinic.

\section{Disclosures}

The authors declare no conflicts of interest.

\section{Acknowledgments}

The authors thank the Portuguese Foundation for Science and Technology (FCT) Strategic Project of UID/BIO/04469/2013 unit, the project RECI/BBB-EBI/0179/2012 (FCOMP-01-0124-FEDER027462) and the Project "BioHealth - Biotechnology and Bioengineering approaches to improve health quality", Ref. NORTE-07-0124-FEDER-000027, co-funded by the Programa Operacional Regional do Norte (ON.2 - O Novo Norte), QREN, FEDER. JPS acknowledges the FCT for the financial support provided by grant SFRH/BPD/64958/2010. Funding for this project also came from a private donor to M.M.G. We also thank the Genomics core facility and the Stem Cell Center core facility at the University of California, Riverside for the use of FACS Aria and Luminex 200 respectively.

\section{Appendix A. Supplementary data}

Supplementary data associated with this article can be found, in the online version, at http://dx.doi.org/10.1016/j.actbio.2015.07. 043.

\section{References}

[1] G. Chaby, P. Senet, M. Vaneau, P. Martel, J.-C. Guillaume, S. Meaume, et al. Dressings for acute and chronic wounds: a systematic review, Arch. Dermatol. 143 (2007) 1297-1304.

[2] World Health Organization. WHO Plan for Burn Prevention and Care 2008

[3] S. Gist, T.-M. Iris, S. Falzgraf, S. Cameron, M. Beebe, Wound care in the geriatric client, Clin. Interv. Aging 4 (2009) 269-287.

[4] D. Okan, K. Woo, E.A. Ayello, G. Sibbald, The role of moisture balance in wound healing, Adv. Skin Wound Care 20 (2007) 39-53.

[5] J. Wasiak, H. Cleland, F. Campbell, A. Spinks, Dressings for superficial and partial thickness burns, The Cochrane database of systematic reviews 2013, vol. 3, pp. CD002106.
[6] Y.B. Kwon, H.W. Kim, D.H. Roh, S.Y. Yoon, R.M. Baek, J.Y. Kim, et al., Topical application of epidermal growth factor accelerates wound healing by myofibroblast proliferation and collagen synthesis in rat, J. Vet. Sci. 7 (2006) 105-109.

[7] Y. Liu, M. Petreaca, M. Martins-Green, Cell and molecular mechanisms of insulin-induced angiogenesis, J. Cell Mol. Med. 13 (2009) 4492-4504.

[8] M. Hrynyk, M. Martins-Green, A.E. Barron, R.J. Neufeld, Alginate-PEG sponge architecture and role in the design of insulin release dressings, Biomacromolecules 13 (2012) 1478-1485.

[9] K.C. Broussard, J.G. Powers, Wound dressings: selecting the most appropriate type, Am. J. Clin. Dermatol. 14 (2013) 449-459.

[10] R.A. Dorschner, V.K. Pestonjamasp, S. Tamakuwala, T. Ohtake, J. Rudisill, V. Nizet, et al., Cutaneous injury induces the release of cathelicidin anti-microbial peptides active against Group A Streptococcus, J. Invest. Dermatol. 117 (2001) 91-97.

[11] U.H.N. Durr, U.S. Sudheendra, A. Ramamoorthy, LL-37, the only human member of the cathelicidin family of antimicrobial peptides, Biochim. Biophys. Acta 1758 (2006) 1408-1425.

[12] R. Koczulla, G. von Degenfeld, C. Kupatt, F. Krotz, S. Zahler, T. Gloe, et al, An angiogenic role for the human peptide antibiotic LL-37/hCAP-18, J. Clin. Invest. 111 (2003) 1665-1672.

[13] R. Ramos, L. Domingues, M. Gama, Escherichia coli expression and purification of LL37 fused to a family III carbohydrate-binding module from Clostridium thermocellum, Protein Expr. Purif. 71 (2010) 1-7.

[14] R. Ramos, J.P. Silva, A.C. Rodrigues, R. Costa, L. Guardão, F. Schmitt, et al., Wound healing activity of the human antimicrobial peptide LL37, Peptides 32 (2011) 1469-1476.

[15] C.D. Ciornei, T. Sigurdardottir, A. Schmidtchen, M. Bodelsson, Antimicrobial and chemoattractant activity, lipopolysaccharide neutralization, cytotoxicity, and inhibition by serum of analogs of human cathelicidin LL-37, Antimicrob. Agents Chemother. 49 (2005) 2845-2850.

[16] I. Nagaoka, K. Kuwahara-Arai, H. Tamura, K. Hiramatsu, M. Hirata, Augmentation of the bactericidal activities of human cathelicidin CAP18/LL37-derived antimicrobial peptides by amino acid substitutions, Inflamm. Res. 54 (2005) 66-73.

[17] H. Kim, J.H. Jang, S.C. Kim, J.H. Cho, De novo generation of short antimicrobial peptides with enhanced stability and cell specificity, J. Antimicrob. Chemother. 69 (2014) 121-132.

[18] K. Knop, R. Hoogenboom, D. Fischer, U.S. Schubert, Poly(ethylene glycol) in drug Delivery: pros and cons as well as potential alternatives, Angew. Chem. Int. Ed. 49 (2010) 6288-6308.

[19] D. Hreczuk-Hirst, D. Chicco, L. German, R. Duncan, Dextrins as potential carriers for drug targeting: tailored rates of dextrin degradation by introduction of pendant groups, Int. J. Pharm. 230 (2001) 57-66.

[20] C. Gonçalves, J.A. Martins, F.M. Gama, Self-assembled nanoparticles of dextrin substituted with hexadecanethiol, Biomacromolecules 8 (2007) 392-398.

[21] J.E. Frampton, G.L. Plosker, Icodextrin: a review of its use in peritoneal dialysis, Drugs 63 (2003) 2079-2105.

[22] J. Hardwicke, E.L. Ferguson, R. Moseley, P. Stephens, D.W. Thomas, R. Duncan, Dextrin-rhEGF conjugates as bioresponsive nanomedicines for wound repair, J. Control Release 130 (2008) 275-283.

[23] M.T. Islam, N. Rodriguez-Hornedo, S. Ciotti, C. Ackermann, Rheological characterization of topical carbomer gels neutralized to different $\mathrm{pH}$, Pharm. Res. 21 (2004) 1192-1199.

[24] S. Jettanacheawchankit, S. Sasithanasate, P. Sangvanich, W. Banlunara, P. Thunyakitpisal, Acemannan stimulates gingival fibroblast proliferation; expressions of keratinocyte growth factor-1, vascular endothelial growth factor, and type I collagen; and wound healing, J. Pharmacol. Sci. 109 (2009) 525-531.

[25] D. Hreczuk-Hirst, L. German, R. Duncan, Dextrins as carriers for drug targeting: reproducible succinoylation as a means to introduce pendant groups, J. Bioact. Compat. Polym. 16 (2001) 353-365.

[26] W.J. Waddell, A simple ultraviolet spectrophotometric method for the determination of protein, J. Lab. Clin. Med. 48 (1956) 311-314.

[27] Y. Liu, X. Zhang, Z. Zhang, P.Y. Fang, W.S. Xu, Effects of topical application of insulin on the wound healing in scalded rats, Chin. J. Burns 20 (2004) 98-101.

[28] C.K. Sen, The general case for redox control of wound repair, Wound Repair Regen. 11 (2003) 431-438.

[29] I.N. Zelko, T.J. Mariani, R.J. Folz, Superoxide dismutase multigene family: a comparison of the CuZn-SOD (SOD1), Mn-SOD (SOD2), and EC-SOD (SOD3) gene structures, evolution, and expression, Free Radic. Biol. Med. 33 (2002) 337-349.

[30] M. Valko, D. Leibfritz, J. Moncol, M.T.D. Cronin, M. Mazur, J. Telser, Free radicals and antioxidants in normal physiological functions and human disease, Int. J. Biochem. Cell Biol. 39 (2007) 44-84.

[31] G. Bergers, S. Song, The role of pericytes in blood-vessel formation and maintenance, Neuro Oncol. 7 (2005) 452-464.

[32] S. Guo, L.A. DiPietro, Factors affecting wound healing, J. Dent. Res. 89 (2010) 219-229.

[33] B. Behm, P. Babilas, M. Landthaler, S. Schreml, Cytokines, chemokines and growth factors in wound healing, J. Eur. Acad. Dermatol. Venereol. 26 (2012) $812-820$.

[34] B.A. Mast, G.S. Schultz, Interactions of cytokines, growth factors, and proteases in acute and chronic wounds, Wound Rep. Regen. 4 (1996) 411-420.

[35] J. Distler, A. Hirth, M. Kurowska-Stolarska, R.E. Gay, S. Gay, O. Distler, Angiogenic and angiostatic factors in the molecular control of angiogenesis, Q. J. Nucl. Med. 41 (2003) 149-161. 
262

J.P. Silva et al./Acta Biomaterialia 26 (2015) 249-262

[36] H. Kubo, T. Hayashi, K. Ago, M. Ago, T. Kanekura, M. Ogata, Temporal expression of wound healing-related genes in skin burn injury, Leg. Med. 16 (2014) 8-13.

[37] C.P. Schneider, M.G. Schwacha, I.H. Chaudry, The role of interleukin-10 in the regulation of the systemic inflammatory response following traumahemorrhage, Biochim. Biophys. Acta 1689 (2004) 22-32.

[38] M.G. Tonnesen, X. Feng, R.A. Clark, Angiogenesis in wound healing, J. Invest. Dermatol. 5 (2000) 40-46.

[39] S. Hettiaratchy, P. Dziewulski, ABC of burns. Introduction, Br. Med. J. 328 (2004) 1366-1368.

[40] D. Church, S. Elsayed, O. Reid, B. Winston, R. Lindsay, Burn wound infections, Clin. Microbiol. Rev. 19 (2006) 403-434.

[41] G.D. Mogosanu, A.M. Grumezescu, Natural and synthetic polymers for wounds and burns dressing, Int. J. Pharm. 463 (2014) 127-136.

[42] L.B. Aydogan, M. Kiroglu, U. Tuncer, L. Soylu, The wound amylase concentration in the prediction of pharyngocutaneous fistula, Otolaryngol Head Neck 129 (2003) 414-416.

[43] J.C. Santos, S. Silva-Gomes, J.P. Silva, F.M. Gama, G. Rosa, R.L. Gallo, R. Appelberg, Endogenous cathelicidin production limits inflammation and protective immunity to Mycobacterium avium in mice, Immun. Inflamm. Dis. 2 (2014) 1-12.

[44] A.A. Mohammadi, A. Bakhshaeekia, P. Alibeigi, M.J. Hasheminasab, H.R. Tolideei, A.R. Tavakkolian, et al., Efficacy of propranolol in wound healing for hospitalized burn patients, J. Burn Care Res. 30 (2009) 1013-1017.

[45] A. Parihar, M.S. Parihar, S. Milner, S. Bhat, Oxidative stress and anti-oxidative mobilization in burn injury, Burns 34 (2008) 6-17.

[46] K.K. Griendling, D. Sorescu, B. Lassegue, M. Ushio-Fukai, Modulation of protein kinase activity and gene expression by reactive oxygen species and their role in vascular physiology and pathophysiology, Arterioscler. Thromb. Vasc. Biol. 20 (2000) 2175-2183.

[47] J.W. Baynes, Role of oxidative stress in development of complications in diabetes, Diabetes 40 (1991) 405-412.
[48] A. Elgawish, M. Glomb, M. Friedlander, V.M. Monnier, Involvement of hydrogen peroxide in collagen cross-linking by high glucose in vitro and in vivo, J. Biol. Chem. 271 (1996) 12964-12971.

[49] W.B. Norbury, M.G. Jeschke, D.N. Herndon, Metabolic changes following major burn injury: how to improve outcome, in: J.-L. Vincent (Ed.), Intensive Care Medicine, Springer, New York, 2006, pp. 514-524.

[50] J.W. Pollard, Trophic macrophages in development and disease, Nat. Rev. Immunol. 9 (2009) 259-270.

[51] E. Dejana, G. Bazzoni, M.G. Lampugnani, Vascular endothelial (VE)-cadherin: only an intercellular glue?, Exp Cell Res. 252 (1999) 13-19.

[52] S.A. Eming, T. Krieg, J.M. Davidson, Inflammation in wound repair: molecular and cellular mechanisms, J. Invest. Dermatol. 127 (2007) 514-525.

[53] F.O. Martinez, S. Gordon, The M1 and M2 paradigm of macrophage activation: time for reassessment, F1000Prime Rep 2014, vol. 6, pp. 13.

[54] N. Jetten, S. Verbruggen, M. Gijbels, M. Post, M.J. De Winther, M.P.C. Donners, Anti-inflammatory M2, but not pro-inflammatory $\mathrm{m} 1$ macrophages promote angiogenesis in vivo, Angiogenesis 17 (2014) 109-118.

[55] D.S. Dace, A.A. Khan, J. Kelly, R.S. Apte, Interleukin-10 promotes pathological angiogenesis by regulating macrophage response to hypoxia during development, PLoS ONE 3 (2008) e3381.

[56] P.J. Polverini, Angiogenesis and wound healing: basic discoveries, clinical implications, and therapeutic opportunities, Endod. Top. 24 (2011) $130-145$.

[57] J.W. Penn, A.O. Grobbelaar, K.J. Rolfe, The role of the TGF-beta family in wound healing, burns and scarring: a review, Int. J. Burns Trauma 2 (2012) 18-28.

[58] X.J. Wang, G. Han, P. Owens, Y. Siddiqui, A.G. Li, Role of TGF-beta-mediated inflammation in cutaneous wound healing, J. Invest. Dermatol. 11 (2006) $112-117$.

[59] R. Montesano, L. Orci, Transforming growth factor beta stimulates collagenmatrix contraction by fibroblasts: implications for wound healing, Proc. Natl. Acad. Sci. U.S.A. 85 (1988) 4894-4897. 